\title{
Key Elements Analysis Of Projects' ENVIRONMENTAL IMPACT ASSESSMENT
}

\author{
Vlado Majstorovic, Maja Medic \& Marijana Bandic Glavas
}
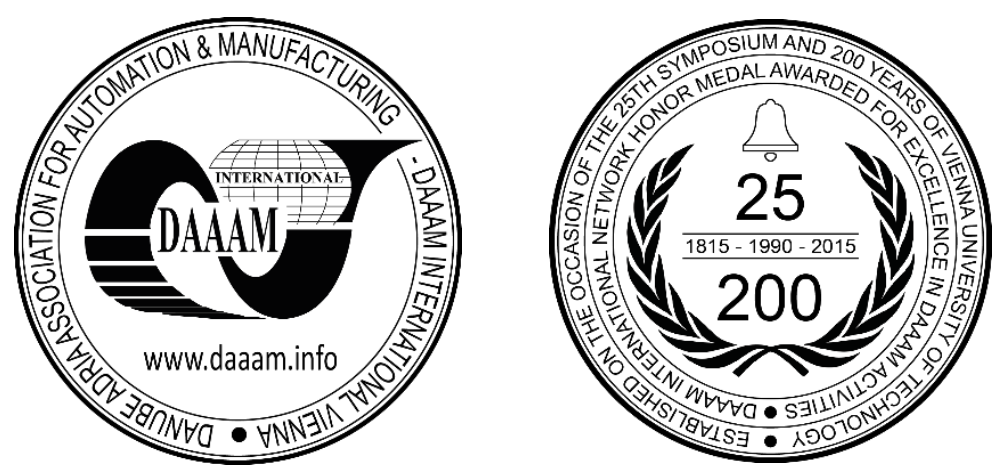

This Publication has to be referred as: Majstorovic, V[lado]; Medic, M[aja] \& Bandic Glavas, M[arijana] (2016). Key Elements Analysis of Projects' Environmental Impact Assessment, Proceedings of the 27th DAAAM International Symposium, pp.0091-0094, B. Katalinic (Ed.), Published by DAAAM International, ISBN 978-3-902734-08-2, ISSN 1726-9679, Vienna, Austria

DOI: $10.2507 / 27$ th.daaam.proceedings.013

\begin{abstract}
In all areas of human activity, the greatest achievements have been achieved by projects. Beside all the positive impacts, some projects impact on the environment negatively. This is why the developed countries of the European Union and the world in their legislature began to regulate environmental protection, bringing numerous legal acts which, among other things, are project related. Guided by this fact, the paper highlights the key elements in the projects' environmental impact assessment and gives a short review of the EU legal framework in this area. Emphasis is placed on the directives on the assessment of the impacts of certain projects on the environment and their amendments. In order to reduce the negative impact on the environment, a substantial number of important elements in the procedures of environmental impact assessment and decision making have been introduced, and the legislation instruments have continuously been reviewed and improved.
\end{abstract}

Keywords: key elements; impact assessment; project; environment; directive.

\section{Introduction}

The 'project' term is used to describe activities that are not carried out continuously but occasionally and optionally. Generally speaking, project can be defined as a set of mutually and logically connected activities of limited duration, aimed to achieve goals being set. Thus, a project can be defined as any process that achieves goal or set of goals. [8] [9] Projects as an economic or social activity are damaging environmental stability, biodiversity, or in any other way (usually negatively) impact on the environment. [11] Therefore, the EU and other world countries have begun creating the laws in order to regulate environmental protection by bring a number of legal acts related to the environmental impact assessment of certain projects.

Environmental impact assessment is the process of evaluating the acceptability of the planned intervention (project) with respect to the environment and determination of necessary environment protection measures to be implemented in the context of preparation of the planned intervention. Usually those are the projects for construction of infrastructural facilities (transport, energy, water), manufacturing and sports facilities, waste management facilities, tourism and catering, shopping centers, interventions that exploit mineral resources, etc. [11] 
The aim of environmental impact assessment is to determine the potential environmental, social and health impacts of implementation of a specific project. The goal is to estimate the physical, biological and socioeconomic impacts in a form that would allow a rational decision-making. [4]

Guided by this fact, this paper provides a short review about the necessity for the legal regulation and a short key elements analysis of projects' environmental impact assessment.

\section{The emergence of the need for legal regulation of the projects' environmental impact assessment}

The first significant legislation in this area - the Law on State policy of the US Environmental Protection was signed in 1970. The adoption of this act triggered the interest of other countries, and from 1973, this process has become a part of the environmental legislation in Canada, from 1975 in future EU countries, namely in Germany, in 1976 in France and Italy, in Luxemburg in 1978, in 1986 in the Netherlands and the United Kingdom, followed by other countries: Norway, Sweden, Finland, Japan, Australia, New Zealand. [7]

The fact that the impact assessment is a necessary instrument for the environmental care and prevention of distortion and degradation of the environment was confirmed by the European Economic Commission in its second action plan for environmental protection in 1977. There, the important role was played by Directive 85/377/EEC from 1985 on the analysis of the effects of certain public and private projects on the environment, which was aimed to harmonize the laws in the EU countries and to contribute to better achievement the EU objectives in the field of environmental protection and life quality. [7]

\section{EU legal framework in the field of environmental protection}

EU legislation in the field of environmental protection (Environmental acquis communautaire) makes about 300 legal acts (directives, regulations and decisions), divided into eleven subsectors that represent the various spheres of environmental management [5]: (1) horizontal legislation; (2) air quality; (3) waste management; (4) water quality; (5) environmental protection; (6) control of industrial pollution and risk management; (7) chemicals and genetically modified organisms; (8) noise; (9) forestry; (10) climate change and (11) civil protection.

Horizontal legislation includes environmental legislation on various issues that are included in different areas of the environment, opposed to the legislation related to every single sector (e.g. air or water). It includes the integration of environmental protection in all economic sectors, strategic assessment of plans and programs, assessment of impact of projects on the environment, access to information and reporting on the implementation of directives about the environment. [4]

The following are directives of horizontal legislation on the assessment of effects of certain projects on the environment and their amendments [2]:

- Directive on the assessment of the effects of projects on the environment 85/377/EEC applies to those projects which may have significant effects on the environment. In this sense, the project means the execution of construction works or other installations or projects in the natural environment and landscape. [1] The EIA Directive 85/377/EEC of 1985 has been amended three times, in 1997, 2003 and 2009:

- Directive 97/11/EC brought the Directive in line with the Espoo Convention on EIA in a Transboundary Context. The Directive of 1997 widened the scope of the EIA Directive by increasing the types of projects covered, and the number of projects requiring mandatory environmental impact assessment (Annex I). It also provided for new screening arrangements, including new screening criteria (at Annex III) for Annex II projects, and established minimum information requirements.

- Directive 2003/35/EC was seeking to align the provisions on public participation with the Aarhus Convention on public participation in decision-making and access to justice in environmental matters.

- Directive 2009/31/EC amended the Annexes I and II of the EIA Directive, by adding projects related to the transport, capture and storage of carbon dioxide $(\mathrm{CO} 2)$.

- Directive 2011/92/EU of the European Parliament and the Council of 13 December 2011 on the assessment of the effects of certain public and private projects on the environment, as amended, known as the "EIA" (environmental impact assessment) Directive, requires that an environmental assessment to be carried out by the competent national authority for certain projects which are likely to have significant effects on the environment by virtue, inter alia, of their nature, size or location, before development consent is given. The projects may be proposed by a public or private person.

- Directive 2014/52/EU of the European Parliament and the Council from April 16th 2014 amending Directive 2011/92/EU on the assessment of the effects of certain public and private projects on the environment. In order to strengthen the quality of the process of environment impact assessment, to harmonize this process with the principles of quality regulation and improve connections and synergies with other legislation and policies of the Union as well as strategies and policies that have been developed by Member States in the areas of national jurisdiction, it was necessary to amend the previous Directive from 2011.

Besides the above mentioned directives, the legal framework for environmental impact assessment includes international conventions because of which the directives have been amended: the Espoo, Aarhus and Kiev. 
In 1991, in Espoo, Finland, the Convention on Environmental Impact Assessment in a Transboundary Context was adopted. The Convention sets out obligation of the parties to assess the impact of certain activities on the environment at an early stage of planning. It also obliges states to notify and consult each other in all major projects being under consideration which may have significant environmental impact across national borders. By convention, the neighboring countries have the right to participate in the environmental impact assessment if the planned project in one country can have an impact on the environment across its borders. [5]

Convention on Access to Information, Public Participation in Decision-making and Access to Justice in Environmental Matters was adopted in Aarhus, Denmark, in 1998. The Aarhus Convention is an international agreement which defines common standards the public's right to information, participation and access to justice. The aim was to contribute to protection of the rights of every person in present and future generations to live in the environment suitable for their health and well-being. [5]

Protocol on Strategic Environmental Assessment with the Convention on Environmental Impact Assessment in a Transboundary Context, was adopted in Kiev 2003. It aims to provide a high level of environmental protection, including health. Parties are required to provide a procedure that includes public participation. [5]

\section{Key Elements Analysis Of Projects' Environmental Impact Assessment}

When we look in which direction the legislation on environmental impact assessment has been developing, we can see that each new modification of the directive has included a new element to which attention should be payed. Thus, after adoption of the original Directive 85/377/EEC on the assessment of the effects of certain public and private projects on the environment, in 1997 the need for its modification due to compliance with the provisions of the Espoo Convention has been shown. Then the area of operation of the directive was extended to the environmental impact assessment across national borders. The next step was adoption of common standards on the public's right to information, participation and access to justice with the adoption of the Aarhus Convention, and therefore the directive was amended again in 2003. With the third amendment in 2009 the projects related to transportation, capture and storage of carbon dioxide were added into the directive.

After three amendments of the original Directive, by Directive 2011/92/EU in 2011, the EU legislation harmonized the principles for assessing the impact of projects on the environment by introducing minimum requirements with regard to the type of projects that are estimated, the most important obligations of the project coordinators, content of evaluation and participation of competent authorities and the public. It contributes to a high level of environmental protection and human health.

In order to strengthen the quality of the process of environmental impact assessment, to harmonize it with the principles of quality regulation and improve connections and synergies with other legislation and policies of the Union as well as with strategies and policies that have been developed by Member States in areas of national jurisdiction, it was necessary to amend the previous Directive from 2011, and in 2014, Directive 2014/52/EU which amends Directive 2011/92/EU on the assessment of effects of certain public and private projects on the environment was adopted. [6]

Furthermore, trends in environmental impact assessment are increasingly emphasizing the need to include some other elements in assessment procedures and decision-making process. In addition to the earlier inclusion of health and social impacts in environmental assessment, some even more important elements that have been emphasized in recent decade are: resource efficiency and sustainability; conservation of biological diversity; climate changes; risks of accidents and disasters; impact on the land; protection of marine environment; protection and promotion of cultural heritage and others.

More extensive studies of effectiveness and sustainability of resources have been included in the review of Directive 2011/92/EU.

There is also a need to assess significant adverse impacts of projects on biodiversity, in order to avoid or reduce their environmental impact to a minimum. [6]

Climate changes will continue to cause harm to the environment and endanger economic development. In this respect, it is appropriate to assess the impact of projects on climate (e.g. emissions of greenhouse gases) and their susceptibility to climate changes. [6]

In order to ensure a high level of environmental protection, it is necessary to take precautions in specific projects that, due to their susceptibility to major accidents and/or natural disasters (such as floods, sea level rise, earth quakes), are likely to have significant adverse impacts on the environment. For such projects it is important to consider their vulnerability (exposure and resistance) to major accidents and/or disasters, the risk of such accidents or disasters and indicators for the likelihood of significant adverse impacts on the environment. [6]

For public and private projects should be considered to limit their impact on the land, especially with regard to land use, and on the ground, including organic matter, erosion, compaction and closure ground. [6]

In order to ensure a high level of protection of marine environment, particularly species and habitats, should be taken into account features of such projects taking into account the used technologies. [6]

For better preservation of historical and cultural heritage and landscape, it is important to deal with the visual impact of projects. [6]

We can see that an environmental impact assessment has a significant effect on numerous projects or their modifications. In addition to positive effects such as the identification of key environmental issues, higher standards of mitigation of adverse consequences, making right decisions, it has its adverse effects. EIA Directive applies only to 
actions, without setting new environmental standards and it does not include stricter financial requirements. Application of environmental impact assessment depends on implementation of its principles into national law. In addition, the environmental impact assessment of individual projects is not enough, there is no alternative locations or methods, the dynamics of the environment and development in general is not processed, and the cumulative effects are ignored as well. [4]

Thus, due to the complexity of some influence and many synergistic effects is not enough to analyze individual object or only certain element but it is necessary make simultaneous analysis of many wider area and all the elements (air, water, soil, biota, etc.). In this respect, the significant is occurrence of strategic environmental impact assessment, which is not related to a specific project but to a much wider system, ultimately the relevant plans and programs which contain and coordinate the many individual projects. [10] It is in a certain way a complement to the environmental impact assessment and it is always current.

Strategic environmental assessment is a procedure that evaluates possible environmental impacts made by strategies, plans and programs, and their alternatives, proposed measures necessary to combat negative impacts, as well as the program of monitoring the impact. Primary purpose is application of process of ensuring sustainable development at a higher level of planning. In the world, it has been applied in the last ten years, and the EU member states, in accordance with the provisions of the Strategic Environmental Assessment (SEA) Directive 2001/42/EC from 2001, have been obliged to apply it since 2004. [3]

SEA Directive is an extension of EIA directive that raises individual projects on the level of plan and programme. The difference between these two directives is that SEA Directive is applied only in public programs which make political decision makers directly responsible for a negative impact on the environment. [4]

Therefore we can say that the EIA is an administrative instrument that applies to the particular project and represents a lower level of decision-making, and SEA is an advisory instrument of higher level of decision-making. [5]

In both cases of the environmental impact assessment, it is about procedure to ensure that in the decision on the acceptance of an intervention, plan, program or project, their possible impacts on the environment should be considered.

\section{Conclusion}

The EU Directive 85/377/EEC played an important role in the analysis of a certain public and private projects' environmental impact assessments. Its goal was to mutually harmonize national laws of the EU countries and to improve EU goal reach in the area of environmental protection and life quality.

After three amendments to the original Directive, the Directive from 2011 harmonized principles for assessing the impact of projects on the environment. In order to strengthen the quality of the projects' environmental impact assessment, then to synchronize the principles of quality regulation and to improve the coherence and synergies with other legislation and policies of the Union as well as with the strategies and policies developed by the Member States in the areas of national jurisdiction, it was necessary to modify the previous directive.

Every modification is driven by the necessity for the inclusion of the new elements in projects' environmental impact assessment. With the increased number of important elements in the procedures of environmental impact assessment and decision making and continuous review and improving instruments of legislation, aims at reducing the negative impact on the environment.

In order to reduce the negative impact on the environment, it is necessary to introduce a substantial number of important elements in the procedures of environmental impact assessment and decision making, as well as it is to continuously review and improve the legislation instruments.

\section{References}

[1] Access to the legislation of the European Union, Council Directive 85/337/EEC, Available from: http://eurlex.europa.eu/LexUriServ/LexUriServ.do?uri=OJ:L:1985:175:0040:0048:EN:PDF, Accessed: 2016-06-17

[2] European Commission (2013), Assessing the impact of projects on the environment, Available from: http://ec.europa.eu/environment/eia/pdf/eia_case_law.pdf, Accessed: 2016-06-10

[3] CARDS2003 (2003), Assessment of Development Strategies on Environment, Strategic Environmental Assessment, Available from: http://www.zavod.pgz.hr/docs/zzpuHR/documents/139/Original.pdf, Accessed: 2016-06-20

[4] Črnjar, M. \& Črnjar, K. (2009), Management of Sustainable Development (economy - ecology - environmental protection), University of Rijeka, Rijeka

[5] Herceg, N. (2013), Environment and Sustainable Development, University of Mostar, Mostar

[6] Official Journal of the European Union (2014), Directive 2014/52/EU of the European Parliament and of the Council, Available from: http://eur-lex.europa.eu/legal-content/EN/TXT/?uri=uriserv:OJ.L_.2014.124.01.0001.01.ENG, Accessed:2016-07-10

[7] Hodolić, J., Badida M., Majernik M. \& Šebo D. (2005), Mechanical Engineering in Environmental Protection, Faculty of Technical Sciences in Novi Sad, Novi Sad

[8] Majstorović, V. (2010), Project Management, University of Mostar, Mostar

[9] Majstorović V., (2001), Upravljanje proizvodnjom i projektima (Production and Project Management), DAAAM International Vienna and University of Mostar

[10] Malbaša, N. \& Jelavić V. (2013), History and current problems of environmental impact assessment in Croatia, First Regional Conference On Environmental Impact Assessment, Zadar

[11] Rajković, D. (2011) Cost-benefit analysis of the environmental impact assessment. University of Zagreb, Zagreb 